\title{
Predictors of Obstetric Anal Sphincter Injury during waterbirth: A secondary analysis of a prospective observational study
}

\author{
Ethel Burns ${ }^{1}$ \\ Laura Price ${ }^{2}$ \\ Jane Carpenter ${ }^{1}$ \\ Lesley Smith ${ }^{3}$ \\ 1 Oxford School of Nursing and Midwifery, Faculty of Health and Life Sciences, Oxford Brookes \\ University, Marston Road, Oxford OX3 OFL \\ 2 Royal United Hospitals Bath NHS Foundation Trust, Patient Safety Department, Mary Ward, Combe \\ Park, Bath, BA1 3NG \\ 3 Institute of Clinical and Applied Health Research, Faculty of Health Sciences, University of Hull, \\ Hull, HU6 7RX \\ Corresponding author: jane.carpenter@brookes.ac.uk
}

\section{FINANCIAL DISCLAIMER/CONFLICT OF INTEREST: NONE}

\section{Author contribution:}

Burns: Undertook original observation study. Project development, data collection, data analysis, manuscript editing

Price: Initial data analysis as part of BSc thesis, manuscript writing (first draft).

Carpenter: Final data analysis, manuscript writing (subsequent drafts), manuscript editing Smith: Project development, data analysis, manuscript editing. 


\section{ABSTRACT}

Introduction and Hypothesis: Obstetric Anal Sphincter Injury (OASI) during childbirth is associated with urino-genital pain and dysfunction. Waterbirth is a popular birth choice for women, but controversy remains around the risk of OASI during waterbirth. This study reports on the incidence of OASI, and factors associated with OASI, for a cohort of women who gave birth in water.

Methods: This secondary analysis used prospectively collected data from 2,908 women who gave birth in water in the hospital setting. Incidence of OASI was calculated. Univariable and multivariable logistic regression analysis evaluated factors associated with OASI.

Results: The incidence of OASI was $1.9 \%(95 \% \mathrm{Cl} 1.4,2.4)$ for all women. In nulliparae it was higher $(3.2 \%, 95 \% \mathrm{Cl} 2.3,4.3)$, than for multiparae $(0.9 \%, 95 \% \mathrm{Cl} 0.5,1.4)$. In the multivariable analysis two variables were associated with OASI; multiparity was negatively associated with OASI (aOR $0.24,95 \%$ $\mathrm{Cl} 0.12,0.50, \mathrm{p}<0.001$ ), and birth weight was positively associated with OASI (aOR $1.001,95 \% \mathrm{Cl}$ $1.000,1.002, p=0.02$ ). A 'hands-on' technique was used during only $13 \%$ of births. Birth position supporting a flexible sacrum did not influence OASI risk.

Conclusions: A low incidence of OASI was found for this cohort of women. The low proportion of midwives using a hands-on technique suggests that it may not be required in waterbirth.

\section{KEYWORDS}

Birthing pool, OASI, perineal trauma, severe perineal trauma, waterbirth.

\section{SUMMARY}

Brief summary (25 words)

Incidence of obstetric anal sphincter injury was low (1.9\%) in 2,908 women who had a waterbirth. Multiparity was protective while birthweight was a risk factor. 


\section{INTRODUCTION}

Severe perineal trauma, often referred to as Obstetric Anal Sphincter Injury (OASI) is associated with short and long-term morbidity, such as perineal pain [1-3], dyspareunia [2-4] and anal incontinence $[5,6]$. The true prevalence of OASI is unclear, with studies reporting values from $2.3 \%$ [3] to $11 \%$ [7]. However, given that OASI is considered to be the leading cause of faecal incontinence in childbearing women [8], and that there is an apparent increasing trend in OASI prevalence [9], prevention of OASI wherever possible is a clinical priority.

In the UK, the increased reported incidence of OASI has resulted in a recommendation by the Royal College of Obstetricians and Gynaecologists (RCOG) that for spontaneous vaginal birth midwives apply pressure to the fetal head and the perineum $[10,11]$. The OASI Care Bundle is based on observational research [9]. However, a Cochrane review including 20 randomised controlled trials of 15,181 women did not show a difference in OASI for women who received hands on pressure to the fetal head compared with hands off or poised [12]. Factors shown to be consistently associated with an increased risk of OASI include instrumental delivery [13-18], with forceps associated with a higher risk than ventouse [13-16], longer duration of second stage of labour [14,18,19], nulliparity $[12,14,19,20-22]$, large for gestational age or birthweight $[10,12,16,20,21,23]$, and occipito posterior (OP) position $[21,22]$.

For women who choose to give birth in water, there is divergent evidence on risk of sustaining OASI with some suggesting that birth in water results in higher incidence of OASI [24,25] and some showing the converse [26-28]. The study by Preston et al. [25], showed an increased risk of OASI for waterbirth (3.3\%) versus spontaneous birth on land (1.6\%), but it was a retrospective design and excluded women who had an episiotomy. The prognostic model did not include maternal birth position in the pool or style of pushing [3]. 
The current study is a secondary analysis of data from a prospective observational study. The aim is to report the incidence of OASI, and to investigate factors associated with OASI, for a cohort of women who gave birth in water.

\section{METHODS}

\section{Study design}

This was a secondary analysis of data collected by a prospective observational study [29] which described the characteristics, interventions and maternal and neonatal outcomes by planned place of birth for pregnant women who used a birthing pool.

\section{Setting and participants}

Full methods for the original study can be found in the published article [29]. In summary, descriptive data were collected for 8,924 women who entered a birthing pool during labour. Twentysix National Health Service Hospital Trusts provided data collected between 2000 and 2008. Place of birth included Obstetric Units (OU); Alongside Midwifery Units (AMU); Freestanding Midwifery Units (FMU) and midwife-attended home births. Birthing pool dimensions were ascertained to ensure that they were sufficiently large to enable a woman to adopt a range of different positions.

This secondary analysis included data for 2,908 women who had a waterbirth (defined as the neonate being born spontaneously under the water) in an OU $(N=1,860)$ or $A M U(N=1,048)$. We were unable to include the community setting (FMU and home births) due to insufficient OASI events ( $n=12$ from 1,783 waterbirths). Women were excluded from the sample if they had a previous caesarean section; breech presentation or an induction of labour because these characteristics present risk factors that predispose women to an increased likelihood of operative delivery [25].

A range of characteristics, interventions and maternal and neonatal outcomes were recorded. To identify incidence of OASI, perineal trauma was assessed and classified by the attending midwife 
and/or obstetrician according to criteria described by Kettle and Tohill [30]. This was recorded as; intact perineum (no trauma to labia, vagina or perineum), first degree (involving the perineal skin only), second degree (involving the perineal muscles and subcutaneous fat with or without perineal skin), OASI (defined as any tear in the anal sphincter, 3A, 3B, 3C and fourth degree extension into the rectal epithelium), and episiotomy [30]. In the UK, obstetricians and midwives are advised to perform a digital anal examination to check for any anal sphincter fibre damage in the presence of a second degree tear or episiotomy, and if found, refer to an obstetrician who has been trained to repair OASI [10].

Outcome data for the 2,908 women included in the secondary analysis, along with relevant maternal or neonatal characteristics, interventions and events were extracted from the original database and imported into Statistical Package for Social Sciences (SPSS) version 24 (2016) for analysis.

\section{Statistical analysis}

Descriptive statistics of the characteristics and outcomes of women and neonates are provided. Frequencies and percentages were calculated for categorical variables, the mean with standard deviation was calculated for continuous variables, after assessing the distribution.

A variable was selected for inclusion in the logistic regression model if it was clinically plausible for it to influence the likelihood of OASI, and sufficient data were available. Data for ethnicity, BMI, OP position and style of pushing were not collected as part of the original study, and so could not be included in the model.

Categorical predictor variables included in the model were parity (nulliparae vs multiparae, with nulliparous as the reference), place of birth (OU vs AMU with OU as the reference) birth position (non-flexible sacrum vs flexible sacrum, with non-flexible sacrum as the reference). Positions that aim to expand the pelvic outlet and take weight off the sacrum, including the coccyx, are defined as flexible sacrum [3]. Flexible sacrum positions were kneeling, all-fours, lateral and supine in the pool. 
Non-flexible sacrum positions were semi-recumbent and sitting. The intention was to also include perineal care technique ('hands-on' or 'hands-off' the perineum during birth). However, there were insufficient occurrences of 'hands-on' ( $n=2 / 54$ in the OASI group and $n=375 / 2854$ in non-OASI group and) prohibiting inclusion in the model.

Continuous variables included maternal age (years), duration of time in water (minutes), duration of second stage (minutes) and birth weight (grams). We did not categorise these variables due to the absence of clear clinical evidence to determine thresholds for such categories.

Multicollinearity was assessed using VIF scores in SPSS. There was no evidence of multicollinearity found via VIF scores; all scores were below 1.5 which is well below the threshold of concern. First, univariable logistic regression analyses were run with OASI as the response variable; then all potential explanatory variables were added to a multivariable model using the ENTER method. A pvalue of $<0.05$ was considered to be statistically significant. The strength and direction of association of explanatory variables with OASI is presented using odds ratios (OR) and 95\% confidence intervals $(95 \% \mathrm{Cl})$. Analyses were carried out for women with complete data. All analyses were performed using Statistical Package for the Social Science (SPSS) (Version 25.0; IBM, Armonk, NY, USA)

\section{Ethical consideration}

The study was approved by Oxford Brookes University's Research Ethics Review Group, who at the time advised that consent from the women involved in the observational study was not required (data collection period 2002-2008). Individual study centres determined whether there was a need for local ethics approval. 


\section{RESULTS}

\section{Descriptive statistics}

The participant flow diagram, outlining how the final sample size was determined for the secondary analysis, is shown in Figure 1. Table 1 shows the overall incidence of the different types of perineal trauma, stratified by parity. There was a higher incidence of intact perineum $(38.6 \%$ vs $19.8 \%$ respectively) and first-degree tear (16.3\% vs $22.7 \%$ respectively) in multiparae compared to nulliparae, and a lower incidence of other trauma (18.9\% vs 9.3\%) (Table 1$)$.

There were 54 cases of OASI overall, giving an incidence of $1.9 \%(95 \% \mathrm{Cl} 1.4,2.4)$. Higher incidence was observed in nulliparae $(3.2 \%, 95 \% \mathrm{Cl} 2.3,4.3)$, compared to multiparae $(0.9 \%, 95 \% \mathrm{Cl} 0.5,1.4$, Table 1). As would be expected during waterbirth, episiotomy was an extremely rare event $(0.3 \%$ of multiparae and $0.6 \%$ of nulliparae, Table 1 ), but occurred nonetheless.

Descriptive statistics for other factors are shown in Table 2, stratified by parity due to the known influence of parity on pregnancy outcome [31]. Nulliparous women were more likely to adopt nonflexible sacrum positions than multiparous women (nulliparae $58.0 \%, 95 \% \mathrm{Cl} 55.2,60.7$; multiparae $50.1 \%, 95 \% \mathrm{Cl} 47.7,52.5$, Table 2$)$.

\section{Logistic regression}

Seven variables were tested for a potential association with OASI (Table 3). In the unadjusted univariable analyses, multiparity reduced the likelihood of OASI, and increasing neonatal birth weight and duration of second stage increased the likelihood of OASI. Other potential predictive variables showed no significant relationship.

After adjustment for all other predictors via multivariable analysis, multiparity remained strongly associated with reduced likelihood of OASI ( $p<0.001$, Table 3 ). Increasing neonatal birth weight remained positively associated with OASI. Duration of second stage was not associated with OASI in the adjusted analysis. 


\section{DISCUSSION}

The overall OASI incidence of $1.9 \%$ was low in this cohort of women giving birth in water in obstetric units or AMUs in the UK. Factors independently associated with OASI for this cohort of women, via multivariable analysis, are those already identified as risk factors for women giving birth on land namely parity and birthweight $[35,36]$.

The overall low rate we found is comparable to, or lower than, prevalence reported in other studies involving women who had a waterbirth that took place over similar time-periods [33,34], lower than the national rate of $3.5 \%$ for women who give birth to a singleton term baby [32] and $3.3 \%$ of women who sustained OASI during waterbirth reported by Preston et al [25]. This was a retrospective study of 15,734 obstetrically healthy women who birthed at an AMU, undertaken using data from a similar time-period to the current study. A total of 1,244 of these women had a waterbirth. It is unclear if any of the women who had a spontaneous birth on land spent part of their labour in water. If any did do so, this would present a potential confounder in the control group.

Birth position was recorded as either being supportive of, or inhibiting, a flexible sacrum as per Edqvist et al [3]. We were keen to see if this influenced the risk of OASI due to conflicting evidence in the literature. However, we found no evidence of a relationship between birth position and risk of OASI for women who had a waterbirth. This may suggest that any position adopted during waterbirth will enable flexibility of the sacrum, due to buoyancy provided by the water.

We had hoped to include application of 'hands-on' to the perineum by the midwife, or not, as a potential factor due to ongoing controversy on this topic [10-12]. However, a 'hands-on' technique occurred in only $13 \%(n=377)$ of waterbirths with insufficient OASI in the hands-on category to enable analysis. However, the low overall OASI rate of $1.9 \%$ in this study, despite hands-off technique used for the majority of the waterbirths $(87 \%)$, suggests that it does not predispose women to OASI and that hands-on is not a requirement in waterbirth. This warrants further investigation in adequately powered studies with confounding factors controlled for. 


\section{Strengths and limitations}

A strength of this study is that the data came from a large, prospective, multicentre observational study, which for the first time reported on birthing pool use across the range of birth settings and analysed by planned place of birth and maternal parity [29]. There are few published prospective studies investigating waterbirth, with most studies being retrospective. Furthermore, data such as position of the midwifes hands are not available in other similar studies.

However, this was a secondary analysis of a subset of these data, and we were limited by the rarity of OASI in the cohort. For example, there were insufficient OASI in the community (FMU/home birth) setting for its inclusion in the study, even though these women are more likely to access a birthing pool during their labour [37]. In addition, as reported in the methods, we were missing some important demographic characteristics which were not obtained as part of the original study. For example, ethnicity and BMI have been identified as predictive factors for OASI $[25,36]$, but could not be included in our analysis. We did not have data for the style of pushing that the women adopted or OP position; factors that may influence perineal outcome [38]. Although the sample included in the study was large (2,908 women), 458 women were excluded prior to analysis due to missing data; this may have influenced the results obtained. Finally, the original study did not include a control group of women who could have, but chose not to, labour and/or give birth in water. Therefore, we were unable to compare incidence of OASI in these two groups.

\section{CONCLUSION}

A low incidence of OASI was found for this cohort of women. The low proportion of midwives using a hands-on technique suggests that it may not be required in waterbirth. Given the current practice recommendations within the OASI care bundle for midwives to use a hands-on technique this is an interesting finding; and requires further investigation. We found no evidence of a relationship between birth position and risk of OASI for women who had a waterbirth. Waterbirth may, therefore, offer women a birth environment where they can adopt different positions without 
increasing a risk of OASI. There is a lack of prospective studies reporting on OASI during waterbirth across the full range of care settings. This study therefore adds important knowledge to the evidence base on this topic. Nonetheless, further investigation in adequately powered, prospective studies with confounding factors controlled for is warranted. 


\section{Acknowledgements}

We thank the midwives involved in data collection and collation and the women who participated in the study. 


\section{REFERENCES}

1. Macarthur AJ, Macarthur C. Incidence, severity, and determinants of perineal pain after vaginal delivery: a prospective cohort study. Am J Obstet Gynecol. 2004; 191(4): 1199-1204. doi: 10.1016/j.ajog.2004.02.064 [Accessed 14.05.2019]

2. Schytt $E$, Lindmark $G$, Waldenstrom U. Physical symptoms after childbirth: prevalence and associations with self-rated health. BJOG. 2005; 112(2): 210-217. doi: 10.1111/j.14710528.2004.00319.x [Accessed 14.05.2019]

3. Edqvist M, Blix E, Hegaard HK, Ólafsdottir OA, Hildingsson I, Ingversen K, Mollberg M Lindgren H. Perineal injuries and birth positions among 2992 women with a low risk pregnancy who opted for a homebirth. BMC Preg Childbirth 2016; 16: 196. doi 10.1186/s12884-016-0990-0 [Accessed 15.04.19]

4. Rathfisch G, Dikencik BK, Kizilkaya Beji N, Comert N, Tekirdag Al, Kadioglu A. Effects of perineal trauma on postpartum sexual function. J Adv Nurs. 2010; 66(12): 2640-2649. doi: 10.1111/j.13652648.2010.05428.x [Accessed 14.05.2019]

5. Borello-France D, Burgio KL, Ritcher HE, Zyczynski $H$, Fitzgerald MP, Whitehead W, Fine $P$, Nygaard I, Handa VL, Visco AG, Weber AM, Brown MB. Fecal and urinary incontinence in primiparous women. Obstet Gynecol. 2006; 108(4): 863-872. doi: 10.1097/01.AOG.0000232504.32589.3b [Accessed 14.05.2019]

6. LaCross A, Groff M and Smaldone A. Obstetric anal sphincter injury and anal incontinence following vaginal birth: a systematic review and meta-analysis. J Midwifery Womens Health. 2015; 60(1): 37-47. doi: 10.1111/jmwh.12283. [Accessed 14.05.2019]

7. Dudding TC, Vaizey CJ, Kamm MA: Obstetric anal sphincter injury: incidence, risk factors, and management. Ann Surg 2008; 247: 224-237. doi: 10.1097/SLA.0b013e318142cdf4 [Accessed 14.05.2019]

8 Kamm MA. Obstetric damage and faecal incontinence. Lancet 1994; 344(8924): 730-733. http://www.ncbi.nlm.nih.gov/pubmed/7915781 [Accessed 14.05.2019]

9. Gurol-Urganci I, Cromwell DA, Edozien LC, Mahmood TA, Adams EJ, Richmond DH, et al. Third- and fourth-degree perineal tears among primiparous women in England between 2000 and 2012: time trends and risk factors. BJOG 2013; 120: 1516-1525. doi: 10.1111/1471-0528.12363 [Accessed 14.05.2019]

10. Fernando R, Williams A AE. The management of third- and fourth degree perineal tears. RCOG 2015; GTG 29, pp 1-19. Available at: https://www.rcog.org.uk/en/guidelines-researchservices/guidelines/gtg29/ [Accessed 14.05.2019]

11. OASI Care Bundle. https://www.rcog.org.uk/OASICareBundle. [Accessed 11.04.2019]

12. Aasheim V, Nilsen ABV, Lukasse M, Reinar LM. Perineal techniques during the second stage of labour for reducing perineal trauma. Cochrane Database Syst Rev. 2017 Jun 13; 6:CD006672. doi: 10.1002/14651858.CD006672.pub3. [Accessed 14.05.2019]

13. Revicky V, Nirmal D, Mukhopadhyay S, Morris EP, Nieto JJ. Could a mediolateral episiotomy prevent obstetric anal sphincter injury? Eur J Obstet Gynecol Reprod Biol 2010; 150: 142-146. doi: 10.1016/j.ejogrb.2010.03.002 [Accessed 14.05.2019]

14. Sultan $\mathrm{AH}$, Kamm MA, Hudson $\mathrm{CN}$, Bartram $\mathrm{Cl}$. Third degree obstetric anal sphincter tears: risk factors and outcome of primary repair. BMJ 1994; 308: 887-891. doi: 10.1136/bmj.308.6933.887 [Accessed 14.05.2019] 
15. de Leeuw JW, Struijk PC, Vierhout ME, Wallenburg HC. Risk factors for third degree perineal ruptures during delivery. BJOG 2001; 108: 383-387. doi: https://doi.org/10.1111/j.1471-

0528.2001.00090.x [Accessed 14.05.2019]

16. Dahl C, Kjolhede P. Obstetric anal sphincter rupture in older primiparous women: a case-control study. Acta Obstet Gynecol Scand 2006; 85: 1252-1258. doi: 10.1080/00016340600839890 [Accessed 14.05.2019]

17. Voldner N, Froslie KF, Haakstad LA, Bo K, Henriksen T. Birth complications, overweight, and physical inactivity. Acta Obstet Gynecol Scand 2009; 88: 550-555. doi: 10.1080/00016340902818162 [Accessed 14.05.2019]

18. Prager M, Andersson KL, Stephansson O, Marchionni M, Marions L. The incidence of obstetric anal sphincter rupture in primiparous women: a comparison between two European delivery settings. Acta Obstet Gynecol Scand 2008; 87: 209-215. doi: 10.1080/00016340701832661 [Accessed 14.05.2019]

19. Gottvall K, Allebeck $P$, Ekeus $C$. Risk factors for anal sphincter tears: the importance of maternal position at birth. BJOG 2007; 114: 1266-1272. doi: 10.1111/j.1471-0528.2007.01482.x [Accessed 14.05.2019]

20. Lowder JL, Burrows LJ, Krohn MA, Weber AM. Risk factors for primary and subsequent anal sphincter lacerations: a comparison of cohorts by parity and prior mode of delivery. Am J Obstet Gynecol 2007; 196(344): e341-345. doi: 10.1016/j.ajog.2006.10.893 [Accessed 14.05.2019]

21. Groutz A, Hasson J, Wengier A, Gold R, Skornick-Rapaport A, Lessing JB, Gordon D. Third- and fourth-degree perineal tears: prevalence and risk factors in the third millennium. Am J Obstet Gynecol 2010; 204(347): e341-344. doi: 10.1016/j.ajog.2010.11.019 [Accessed 14.05.2019]

22. Rognant S, Benoist G, Creveuil C, Dreyfus M. Obstetrical situations with a high risk of anal sphincter laceration in vacuum-assisted deliveries. Acta Obstet Gynecol Scand 2012; 91: 862-868. doi: 10.1111/j.1600-0412.2012.01401.x [Accessed 14.05.2019]

23. Landy HJ, Laughon SK, Bailit JL, Kominiarek MA, Gonzalez-Quintero VH, Ramirez M, Haberman S, Hibbard J, Wilkins I, Branch DW, et al. Characteristics associated with severe perineal and cervical lacerations during vaginal delivery. Obstet Gynecol 2011; 117: 627-635. doi: 10.1097/AOG.0b013e31820afaf2 [Accessed 14.05.2019]

24. Cortes E, Basra R, Kelleher J. Waterbirth and pelvic floor injury: a retrospective study and postal survey using ICIQ modular long form questionnaires. Eur J Obstet Gynecol Reprod Biol 2011; 155: 2730. doi: 10.1016/j.ejogrb.2010.11.012 [Accessed 14.05.2019]

25. Preston HL, Alfirevic Z, Fowler GE, Lane S. Does water birth affect the risk of obstetric anal sphincter injury? Development of a prognostic model. Int Urogynecol J. 2019; 30(6): 909-915. doi: 10.1007/s00192-019-03879-z. [Accessed 14.05.2019]

26. Dahlen HG, Dowling H, Tracy M, Schmied V, Tracy S. Maternal and perinatal outcomes amongst low risk women giving birth in water compared to six birth positions on land. A descriptive cross sectional study in a birth centre over 12 years. Midwifery 2013; 29(7): 759-64. doi: 10.1016/j.midw.2012.07.002. [Accessed 14.05.2019]

27. Otigbah CM, Dhanjal MK, Harmsworth G, Chard T. A retrospective comparison of water births and conventional vaginal deliveries. Eur J Obstet Gynecol Reprod Biol. 2000; 91(1): 15-20.

http://www.ncbi.nlm.nih.gov/pubmed/10817872. [Accessed 14.05.2019]

28. Henderson J, Burns EE, Regalia AL, Casarico G, Boulton MG, Smith LA. Labouring women who used a birthing pool in obstetric units in Italy: prospective observational study. BMC Pregnancy Childbirth. 2014; 14: 17. doi: 10.1186/1471-2393-14-17. [Accessed 14.05.2019] 
29. Burns EE, Boulton MG, Cluett E, Cornelius VR, Smith LA. Characteristics, interventions, and outcomes of women who used a birthing pool: a prospective observational study. Birth 2012; 39(3): 192-202. doi: 10.1111/j.1523-536X.2012.00548.x. [Accessed 14.05.2019]

30. Kettle C, Tohill S. Perineal Care. BMJ Clinical Evidence. 2008; 09: 1401. https://www.ncbi.nlm.nih.gov/pmc/articles/PMC2907946/ [Accessed 14.05.2019]

31. Bai J, Wong F, Bauman A, Mohsin M. Parity and pregnancy outcomes. Am J Obstet Gynecol. 2002; 86(2): 274-278.

32 NMPA project team. National Maternity and Perinatal Audit: organisational report 2017. RCOG London, 2017.

http://www.maternityaudit.org.uk/downloads/NMPA\%20organisational\%20report\%202017.pdf [Accessed 14.05.2019]

33. Eskandar O, Shet D. Risk factors for 3rd and 4th degree perineal tear. J Obstet Gynaecol. 2009; 29(2): 119-122. doi: 10.1080/01443610802665090 [Accessed 17.04.2019]

34. Geissbuehler V, Stein S, Eberhard J. Waterbirths compared with landbirths: an observational study of nine years. J Perinat Med. 2004; 32(4): 308-14. doi: 10.1515/JPM.2004.057 [Accessed 14.05.2019]

35. Smith LA, Price N, Simonite V, Burns EE. Incidence of and risk factors for perineal trauma: a prospective observational study. BMC Pregnancy Childbirth 2013; 13: 59 http://www.biomedcentral.com/1471-2393/13/59. [Accessed 14.05.2019]

36. Hauck YL, Lewis L, Nathan EA, White $C$ and Doherty DA. Risk factors for severe perineal trauma during vaginal childbirth: A Western Australian retrospective cohort study. Women and Birth 2015. 28: 16-20. doi: 10.1016/j.wombi.2014.10.007 [Accessed 14.05.2019]

37. Lukasse M, Rowe R, Townend J, Knight M, Hollowell J. Immersion in water for pain relief and the risk of intrapartum transfer among low risk nulliparous women: secondary analysis of the Birthplace national prospective cohort study. BMC Pregnancy Childbirth 2014; 14: 60 http://www.biomedcentral.com/1471-2393/14/60. [Accessed 14.05.2019]

38. Lee N, Firmin M, Gao Y, Kildea S. Perineal injury associated with hands on/hands poised and directed/undirected pushing: A retrospective cross-sectional study of non-operative vaginal births, 2011-2016. International Journal of Nursing Studies 2018; 83: 11-17. https://doi.org/10.1016/j.ijnurstu.2018.04.002 [Accessed 14.05.2019] 
Figure Legend:

Figure 1: Participant flow diagram, showing the process used to identify women suitable for inclusion in the secondary analysis. $(F M U=$ Freestanding Midwifery Unit, $A M U=$ Alongside Midwifery Unit, $\mathrm{OU}=$ Obstetric Unit, $\mathrm{CS}=$ Caesarean section)

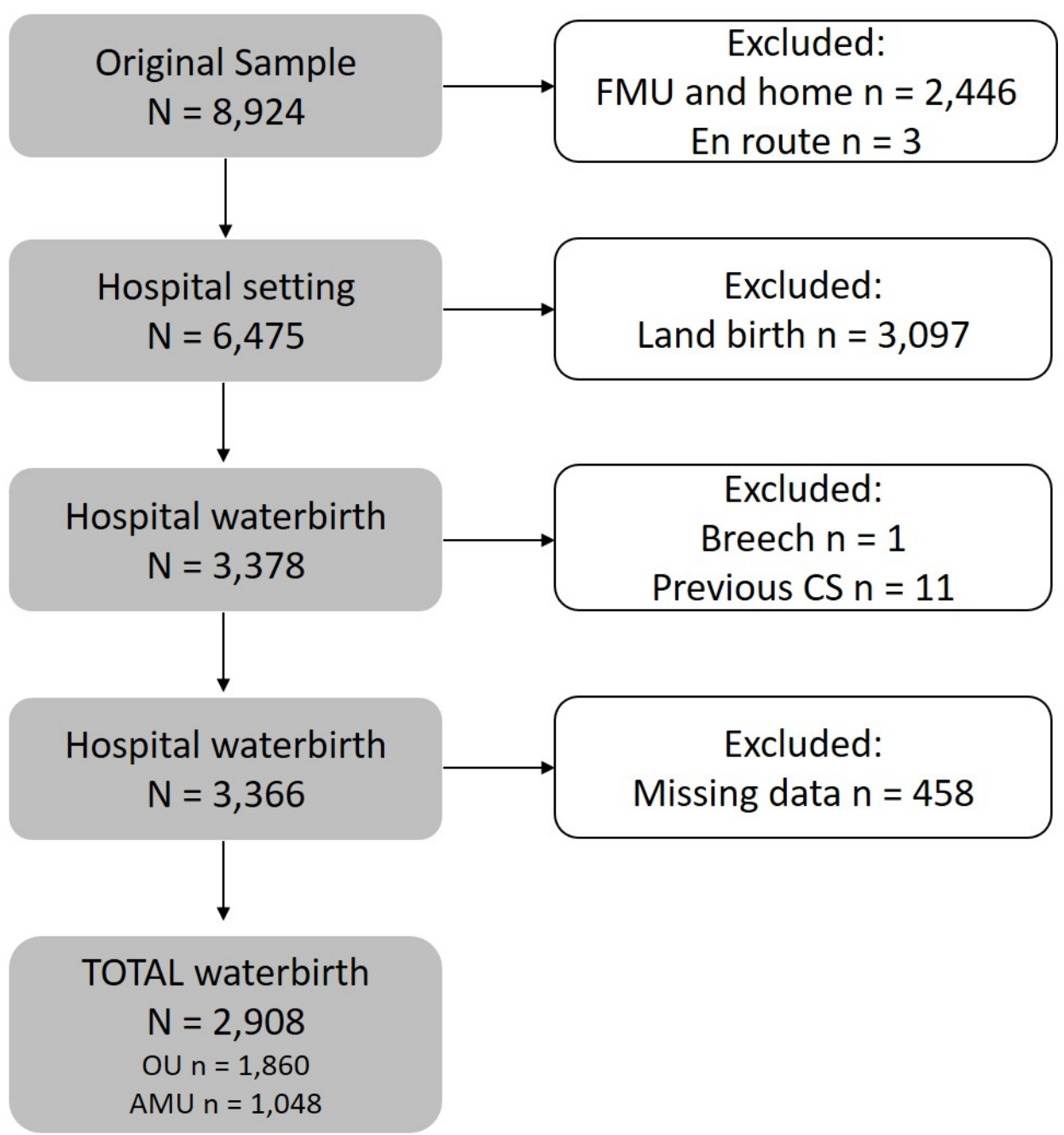


Table 1: Incidence of perineal trauma stratified by parity

\begin{tabular}{|c|c|c|c|c|c|c|}
\hline & \multicolumn{3}{|c|}{$\begin{array}{l}\text { Nulliparae } \\
(n=1,268)\end{array}$} & \multicolumn{3}{|c|}{$\begin{array}{l}\text { Multiparae } \\
(n=1,640)\end{array}$} \\
\hline & $\mathrm{N}$ & $\%$ & $95 \% \mathrm{Cl}$ & $\mathrm{N}$ & $\%$ & $95 \% \mathrm{Cl}$ \\
\hline Intact perineum & 251 & 19.8 & $17.7,22.1$ & 649 & 39.6 & $37.2,42.0^{*}$ \\
\hline First degree & 207 & 16.3 & $14.4,18.5$ & 372 & 22.7 & $20.7,24.8^{*}$ \\
\hline Second degree & 522 & 41.2 & $38.5,43.9$ & 446 & 27.2 & $25.1,29.4^{*}$ \\
\hline Episiotomy & 8 & 0.6 & $0.3,1.3$ & 5 & 0.3 & $0.1,0.7$ \\
\hline OASI & 40 & 3.2 & $2.3,4.3$ & 14 & 0.9 & $0.5,1.4^{*}$ \\
\hline Other ${ }^{\$}$ & 240 & 18.9 & $16.9,21.2$ & 154 & 9.3 & $8.1,10.9$ \\
\hline \multicolumn{7}{|c|}{$\begin{array}{l}\text { OASI = Obstetric Anal Sphincter Injury, } 95 \% \mathrm{Cl}=95 \% \text { Confidence interval. } \\
\$=\text { This includes women who sustained anterior trauma only, eg labial tears, or vaginal } \\
\text { tear only. } \\
*=p<0.05\end{array}$} \\
\hline
\end{tabular}


Table 2: Descriptive statistics for potential predictors of Obstetric Anal Sphincter Injury for women who had a waterbirth stratified by parity

\begin{tabular}{|c|c|c|c|c|c|c|c|}
\hline & & & $\begin{array}{l}\text { Null } \\
\text { (n= }\end{array}$ & $\begin{array}{l}\text { rae } \\
\text { 268) }\end{array}$ & & $\begin{array}{l}\text { Multi } \\
(n=1\end{array}$ & \\
\hline & & & an & SD & & ean & SD \\
\hline Maternal age (years) & & & & 5.4 & & 1.4 & 4.99 \\
\hline Duration of time in pool (mi & iutes) & & 3.7 & 108.2 & & 2.9 & 69.9 \\
\hline Length $2^{\text {nd }}$ stage (minutes) & & & .0 & 33.5 & & 5.2 & 15.9 \\
\hline & & $\begin{array}{l}\text { Nullip } \\
(\mathrm{n}=1\end{array}$ & $\begin{array}{l}\text { rae } \\
\text { 268) }\end{array}$ & & & $\begin{array}{l}\text { Multi } \\
\text { (n }=\end{array}$ & rae \\
\hline & $\mathrm{N}$ & $\%$ & & & $\mathrm{~N}$ & $\%$ & $95 \% \mathrm{Cl}$ \\
\hline Birth position & & & & & & & \\
\hline Flexible sacrum* & 533 & 42.0 & 39. & 44.8 & 818 & 49.9 & $47.5,52.3$ \\
\hline Non-flexible sacrum* & 735 & 58.0 & 55. & 60.7 & 822 & 50.1 & $47.7,52.5$ \\
\hline Midwife hand position & & & & & & & \\
\hline Hands on** & 150 & 11.8 & 10. & 13.7 & 227 & 13.8 & $12.3,15.6$ \\
\hline Hands off** & 1118 & 88.2 & 86. & 89.9 & 1413 & 86.2 & $84.4,87.7$ \\
\hline $\begin{array}{l}\text { SD }=\text { Standard deviation, } 95 \\
* \text { Maternal position at birth, } \\
\text { flexible sacrum positions [3] } \\
* *=\text { Position of midwives' } \\
\text { perineum }\end{array}$ & $\begin{array}{l}6 \mathrm{Cl}=9 \\
\text { where } \\
\text { inds du }\end{array}$ & $\begin{array}{l}\% \text { Cor } \\
\text { positio } \\
\text { ing bi }\end{array}$ & den & $\begin{array}{l}\text { interva } \\
\text { nding th } \\
\text { e fetal } r\end{array}$ & elvic & tlet a & $\begin{array}{l}\text { ermed } \\
\text { ands off the }\end{array}$ \\
\hline
\end{tabular}




\section{Table 3: Predictors of OASI for women who gave birth in water}

\begin{tabular}{|c|c|c|c|c|c|c|c|c|c|}
\hline & & \multirow{2}{*}{$\begin{array}{c}\text { Analysed } \\
\mathrm{N}\end{array}$} & \multirow{2}{*}{$\begin{array}{c}\text { OASI } \\
(\%)\end{array}$} & \multicolumn{3}{|c|}{ Univariable OR (95\% CI) } & \multicolumn{3}{|c|}{ Multivariable OR $(95 \% \mathrm{CI})$} \\
\hline & & & & OR & $95 \% \mathrm{Cl}$ & $p$ & OR & $95 \% \mathrm{Cl}$ & $\mathrm{p}$ \\
\hline \multirow[t]{2}{*}{ Parity } & parous & 1268 & 3.2 & 1.00 & & & & & \\
\hline & parous & 1640 & 0.9 & 0.26 & $0.14,0.49$ & $<0.001$ & 0.24 & $0.12,0.50$ & $<0.001$ \\
\hline \multirow[t]{2}{*}{ Flexible sacrum* } & No & 1557 & 1.9 & 1.00 & & & 1.00 & & \\
\hline & Yes & 1351 & 1.9 & 0.98 & $0.58,1.72$ & 0.98 & 1.06 & $0.61,1.84$ & 0.84 \\
\hline \multirow[t]{2}{*}{ Place of birth } & OU & 1860 & 1.8 & 1.00 & & & & & \\
\hline & AMU & 1048 & 2.0 & 1.13 & $0.65,1.97$ & 0.67 & 1.23 & $0.70,2.15$ & 0.48 \\
\hline \multirow[t]{2}{*}{ Midwife hand position** } & On & 377 & 0.5 & & & & & & \\
\hline & Off & 2531 & 2.1 & & & & & & \\
\hline \multicolumn{2}{|l|}{ Mothers age (years) } & 2908 & $\mathrm{n} / \mathrm{a}$ & 0.98 & $0.93,1.03$ & 0.45 & 1.02 & $0.96,1.01$ & 0.56 \\
\hline \multicolumn{2}{|l|}{ Baby birthweight (grams) } & 2908 & $\mathrm{n} / \mathrm{a}$ & 1.001 & $1.000,1.001$ & 0.04 & 1.001 & $1.000,1.002$ & 0.02 \\
\hline \multicolumn{2}{|c|}{ Total time in pool (minutes) } & 2908 & $\mathrm{n} / \mathrm{a}$ & 1.003 & $1.001,1.005$ & 0.09 & 1.00 & $0.99,1.00$ & 0.81 \\
\hline \multicolumn{2}{|c|}{ Length of second stage (minutes) } & 2908 & $\mathrm{n} / \mathrm{a}$ & 1.01 & $1.00,1.02$ & $<0.001$ & 1.01 & $0.99,1.01$ & 0.25 \\
\hline
\end{tabular}

OASI = Obstetric Anal Sphincter Injury, OR = Odds Ratio, 95\% Cl = 95\% Confidence interval.

* Maternal position at birth, where positions expanding the pelvic outlet are termed flexible sacrum positions [3]

** Position of midwives' hands at birth: hands on or off the perineum. NB: there were insufficient records of hands on to include this variable in the model; overall numbers are provided here for clarity 